\title{
Opioid medication errors in pediatric practice: Four years' experience of voluntary safety reporting
}

\author{
Conor Mc Donnell MD MB BCh BAO FFARCSI
}

\begin{abstract}
$\mathrm{C}$ Mc Donnell. Opioid medication errors in pediatric practice: Four years' experience of voluntary safety reporting. Pain Res Manage 2011;16(2):93-98.
\end{abstract}

BACKGROUND: Opioids are the most common source of drug error that leads to harm in pediatric hospitals.

OBJECTIVE: To undertake a comprehensive review of experience with voluntary safety reports describing pediatric opioid medication errors at The Hospital for Sick Children (Toronto, Ontario), and to characterize the specific opioids involved, severity and type of error described, hospital location and time of day that the error occurred.

METHODS: All medication-related safety reports submitted to an anonymous, voluntary electronic safety reporting database in a university-affiliated pediatric hospital during the first four years of its use were examined. A database of opioid error reports was created for further analysis.

RESULTS: A total of 5935 medication-related safety reports were collected, 507 of which described opioids. Morphine was the most frequently reported opioid, administration was the most frequently reported stage of the medication process (192 errors) and surgical wards were the location from which opioid error was most frequently reported (128 reports). Twenty-two reports described patient harm requiring urgent treatment and intervention. Errors with codeine or hydromorphone resulted in the most significant harm reported. A total of 162 reports described problems with inappropriate opioid disposal, missing opioids, or incorrect opioid counts and checks.

CONCLUSIONS: Future opportunities for improvement in opioid safety should focus on morphine, opioid administration errors in general, the safe disposal of opioids in the hospital environment and the identification of pain as an adverse event.

Key Words: Drug error; Opioids; Pediatrics; Safety

\section{Les erreurs d'opioïdes en pédiatrie : quatre années d'expérience de déclaration volontaire sur la sécurité}

HISTORIQUE : Les opiö̈des sont la principale source d'erreur de
médication qui cause des dommages dans les hôpitaux pédiatriques.
OBJECTIF : Entreprendre une analyse complète de l'expérience des
rapports de sécurité volontaires décrivant les erreurs d'opiö́des en pédiatrie
au Hospital for Sick Children de Toronto, en Ontario, et caractériser les
opiö̈des précis en cause, la gravité et le type d'erreur décrits, le lieu à
l'hôpital et l'heure à laquelle l'erreur s'est produite. MÉTHODOLOGIE : Les chercheurs ont examiné tous les rapports de sécurité liés à des médicaments soumis dans une base de données électronique volontaire et anonyme de déclarations d'un hôpital pédiatrique universitaire pendant les quatre premières années de son utilisation. Ils ont créé une base de données de rapports d'erreur d'opioïdes en vue d'une analyse plus approfondie.

RÉSULTATS : Au total, 5935 déclarations de sécurité liées aux médicaments ont été colligées, dont 507 décrivant des opiö̈des. La morphine était l'opioïde le plus déclaré, l'administration était l'étape du processus de médication où l'on déclarait le plus d'erreurs (192), et c'est dans les services de chirurgie que l'on déclarait le plus d'erreurs d'opioïde (128 déclarations). Vingt-deux déclarations décrivaient des dommages aux patients nécessitant un traitement et une intervention d'urgence. Des erreurs de codéine ou d'hydromorphone s'associaient aux pires dommages déclarés. Au total, 162 déclarations décrivaient des problèmes liés à l'élimination incorrecte d'opioïdes, à des opioïdes manquants ou à un calcul et une vérification incorrects des opioïdes.

CONCLUSIONS : De futures possibilités d'améliorer la sécurité des opioïdes devraient se concentrer sur la morphine, les erreurs d'administration d'opioïdes en général, l'élimination sécuritaire des opioïdes en milieu hospitalier et le signalement de la douleur comme événement indésirable.

identified morphine and fentanyl to be the most commonly reported medications associated with harmful pediatric medication errors. It also described opioids as the most commonly reported therapeutic class associated with harmful pediatric medication errors. The same publication suggested a need to focus on administration and monitoring errors for all medications, particularly human factors and compliance with the 'five rights' of medication administration (the right drug, for the right patient, at the right time, in the right dosage, by the right route) (12). Currently, no literature exists describing experience with voluntary error reports that exclusively describe opioid medication errors in pediatric practice.

A recent report described the use of a focused trigger tool intervention to decrease opioid-related adverse events in 42 children's hospitals in the United States (13). This intervention tool was based on expert opinion and significantly affected factors, such as the overall opioid ADE rate, the incidence of constipation and automated drug-dispensing device overrides, but did not comment on factors such as specific opioids involved, and the type and severity of error encountered. Previous work conducted in neonatal intensive care units (NICUs) working retrospectively from high-frequency and/or high-severity incident reports reverse-engineered a focused adverse event trigger tool specific to the NICU (14). We postulated that a 
comprehensive review of experience with voluntary incident reports describing opioid medication errors at The Hospital for Sick Children (Toronto, Ontario) would provide information that could be used to refine and improve the safety of opioids in this institution. The objective of the present study was to describe the opioids involved, and the circumstances, characteristics and severity of all opioid errors reported voluntarily in the institution since commencement of an online voluntary reporting database.

\section{Setting}

\section{METHODS}

The Hospital for Sick Children is a 300-bed university-affiliated children's hospital serving patients younger than 18 years of age. In addition to providing secondary care to local residents, the hospital is a tertiary referral centre for the province of Ontario and a quaternary centre for the country. Research ethics approval for the present project was granted by The Hospital for Sick Children's Research \& Ethics Board and the department of quality and risk management.

\section{Definitions and safety reporting database}

The National Coordinating Council for Medication Error Reporting and Prevention defines a medication error as follows: "A medication error is any preventable event that may cause or lead to inappropriate medication use or patient harm while the medication is in the control of the health care professional, patient, or consumer. Such events may be related to professional practice, health care products, procedures, and systems, including prescribing; order communication; product labeling, packaging, and nomenclature; compounding; dispensing; distribution; administration; education; monitoring; and use" (15). With this definition in mind, all medication safety reports were examined as submitted to the voluntary, anonymous electronic hospital safety reporting database. Reports specifically describing errors with opioids were searched for and examined. All hospital staff members (physicians, nurses, pharmacists, respiratory therapists, dieticians, domestic staff, etc) are encouraged to use the voluntary reporting database for any errors or incidents considered to be a deviation from normal or expected practice. All managers and clinical leads were educated and requested to promote filling out safety reports if staff members come to them with a complaint, problem, incident or error. The department of quality and risk management introduced the safety reporting database in July 2004 with a number of educational initiatives including ward visits and presentations, hospital-wide e-mails, and face-to-face meetings with clinical leads and department chiefs. Since 2004, further initiatives including educational update seminars, case presentations and learning exercises, and face-to-face meetings with clinical leads and department chiefs have been held to increase rates of reporting and encourage all hospital staff to use the database. The safety reporting system itself is an electronic, online, passwordprotected Adverse Event Management System (CCD Health Systems, USA) and, while minor additions have been made since July 2004, methods of reporting and creating a safety report have remained largely unchanged.

Specifically focusing on medication practices, reports that describe errors related to all phases of the medication process (prescribing, transcribing, dispensing, administering and monitoring) are encouraged. When the database first began in July 2004, anonymous reports were received describing inappropriately 'discarded' opioids and other instances of unsafe practices with regard to the handling of opioids, such as unlocked and untended opioid cabinets, and opioid syringes left in rooms or beds after patient transfers. These reports describe 'errors' of opioid storage, disposal and security. All hospital staff were subsequently encouraged via e-mail messages, messages delivered through their department heads and chiefs, and regular educational updates from the hospital morbidity and mortality oversight committee to continue to report all instances of inappropriate 'handling' of opioids involving either opioids discarded anywhere other than sanctioned medication and 'sharps' bins, and incorrect opioid counts and checks.
The database applies to all patients encountered throughout all clinical and nonclinical areas within the hospital. All safety reports are anonymous, filled out electronically, received, collated and analyzed by the department of quality and risk management. Each safety report is reviewed by quality leads for the clinical area involved and members of the department of quality and risk management. The report is discussed with the clinical leads for the unit involved before a grading of severity is applied and decisions are made with regard to future action plans. Furthermore, all medication-related safety reports are reviewed on a monthly basis by the hospital morbidity and mortality oversight committee, with whom all clinical details are once again verified and confirmed, and agreement is reached on grading of severity and future action plans. Safety reports are not de-identified until six months have passed to facilitate further review and authentification of issues that may have passed to critical review or autopsy. When review is complete or the six-month grace period has elapsed with no further details to examine, the report is de-identified.

All pediatric medication safety reports submitted between July 1 , 2004, and December 31, 2008, were identified and manually searched for the present project by the same investigator. Data describing the type of medication reported were reviewed. All reports describing one or more opioid were further examined, and data that described the location of the incident, specific opioid involved and time of the incident were collected. When reported, data that described observed symptoms, treatment required and patient outcome were also collected. The absence of such descriptions was also documented. The grading of severity as applied by the department of quality and risk management and the hospital morbidity and mortality oversight committee was also documented.

The time of day was divided into three work shifts: 07:00 to 19:00, which represents the elective work period, and 19:00 to midnight and midnight to 07:00, which each represent an out-of-hours reduced staffing presence. The National Coordinating Council for Medication Error Reporting and Prevention index was used for categorizing severity of medication errors to describe opioid medication errors examined in the present study (Appendix 1) (16).

The Hospital for Sick Children defines a highly toxic medication as having a narrow therapeutic range, being available in more than one strength or dose form, having unusual units of measure (eg, micrograms, nanograms or 'units'), having a likelihood of 10 -fold errors, and requiring multiple calculations or dilutions. The Hospital for Sick Children's current list of such medications comprises digoxin, insulin, heparin, morphine and fentanyl.

The type of medication error is described as omission, improper dosage/quantity, unauthorized/wrong drug, prescribing error, wrong administration technique, extra dose, incorrect drug preparation, wrong time, wrong patient, wrong dose form, wrong route, expired product, deteriorated product or mislabelling $(17,18)$.

All data collected were transferred to a Microsoft Excel database (Microsoft Corp, USA) for quantification and further analysis.

\section{RESULTS}

From July 1, 2004, to December 31, 2008, 5935 medication-related safety reports were submitted to the online voluntary reporting database. Safety reports were filed exclusively by members of the nursing staff, physicians, pharmacists, respiratory therapists and domestic staff. The most common therapeutic categories of medications reported were antimicrobials (1525 reports), lipids and parenteral nutrition (401 reports), intravenous fluids (302 reports), chemotherapeutic drugs (289 reports), heparin (218 reports), antiseizure medications (166 reports), electrolytes (153 reports), sedative hypnotics (95 reports) and hormones (66 reports). Opioids were the second most frequently reported category of medications, accounting for 507 of all medication-related safety reports. No duplicate reports were discovered, and all incidents were investigated and verified by the department of quality and risk management, and the hospital morbidity and mortality oversight committee to ensure that details contained within the reports were correct. 
The rate of both opioid reporting and medication reporting per 100 patient days did not increase during the time period studied (Figure 1). Figure 1 also demonstrates that the rate of voluntary reporting for all safety reports (annual mean reporting rate per 100 patient days) decreased in its second year of use (2005), then increased in 2006 and maintained a level of reporting significantly greater than in 2004 and 2005 for all subsequent years studied $(\mathrm{P}<0.05)$.

The most frequently reported opioid was morphine (259 reports). Fentanyl was the next most frequently reported opioid (96 reports), followed by hydromorphone ( 62 reports), codeine (42 reports) and oxycodone (11 reports). Twenty-three reports described other opioids at a frequency of less than five reports for each medication, and 17 reports did not identify a specific opioid. The route of administration most frequently identified in all opioid-related safety reports was intravenous (330 reports). More opioid medication errors were reported on surgical wards (128 reports) than on pediatric medical wards ( 89 reports), the pediatric intensive care unit ( 86 reports), the hematology/oncology unit (62 reports), operating rooms and postanesthesia care unit (59 reports), the NICU (47 reports) and the emergency room (23 reports) (Table 1$)$.

Administration errors were the most frequently reported phase of the medication process for morphine, hydromorphone and fentanyl, but not for codeine (Table 2). Morphine accounted for 126 errors that were reported to have reached the patient but did not cause harm, and 13 of 22 opioid medication errors that caused harm and required intervention and active treatment. Opioid medication errors with harm caused by morphine were reported more often in the pediatric intensive care unit and NICU than in other hospital locations; however, opioid medication errors with harm caused by codeine or hydromorphone were reported more often on surgical wards and in the hematology/oncology unit. Only one report describing harm with fentanyl was identified in the study period. The 22 reports that described patient harm comprised 18 category E reports, two category $F$ reports and one report each for categories $G$ and $\mathrm{H}$. Three of the four most severe incidents reported occurred between 19:00 and midnight, and described errors with codeine or hydromorphone.

A potential for error (category A) was identified in 164 reports $(32.3 \%)$. Of these, 141 category A reports described issues with end-of-work-shift narcotic counts, and inappropriate narcotic storage and/or disposal (Table 3).

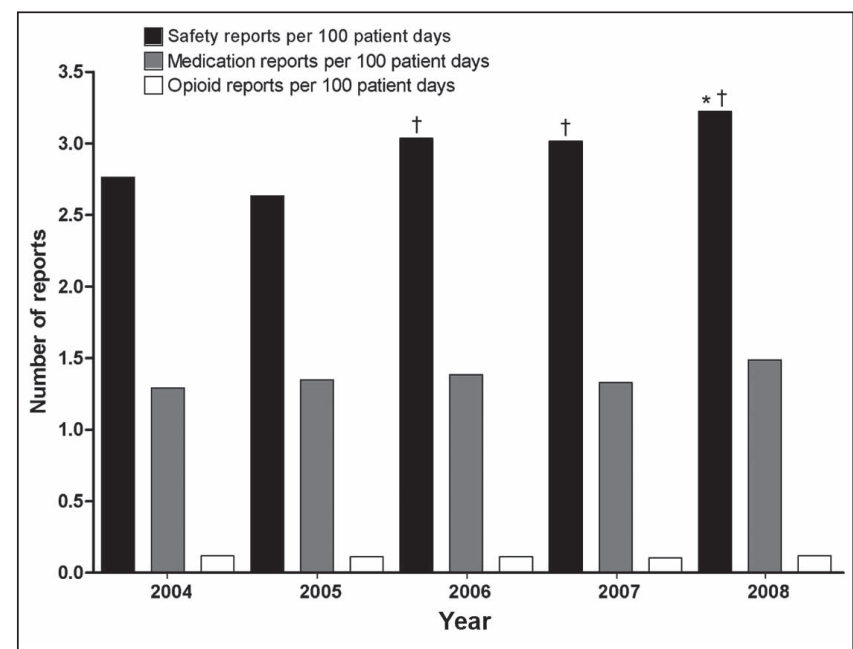

Figure 1) The annual mean reporting rate per 100 patient days of safety reports, medication reports and opioid reports from July 1, 2004, to December 31, 2008. $* P<0.05$ when compared with $2004 ; \quad+P<0.05$ when compared with 2005

Of the 292 opioid medication errors that reached the patient but caused no actual harm, 30 narcotic medication error reports described symptoms and five described more than one symptom. Pain was the most common symptom reported (50\% of all recorded symptoms). Table 4 demonstrates that 14 of the 22 reports describing narcotic medication errors causing harm required medication in addition to oxygen, and four events with reported inadvertent opioid overdosing resulted in prolonged hospital stay.

The most common category of opioid medication errors was improper dosing (148 reports), followed by inappropriate storage/ disposal or inaccurate opioid checks (143 reports), wrong drug (22 reports), nondose-related prescribing error (18 reports), mislabelling (15 reports), misinterpreted order (13 reports), omission and expired products (12 reports each), wrong administration technique and incorrect drug preparation (11 reports each), unavailable equipment (10 reports), extra dose (nine reports), wrong route (eight reports) and inadequate monitoring (six reports). No category was identifiable in 14 safety reports.

\section{TABLE 1}

Location and related severity of opioid safety reports

\begin{tabular}{|c|c|c|c|c|}
\hline Location & Frequency of reporting, $\mathbf{n}(\%)^{*}$ & Category B reports, $\mathbf{n}(\%)^{\dagger}$ & Category C-I reports, $\mathbf{n}(\%)^{\dagger}$ & Category E-I reports, $\mathbf{n}(\%)^{\dagger}$ \\
\hline Surgical wards & $128(25.3)$ & $10(7.8)$ & $81(63.3)$ & $5(3.9)$ \\
\hline Medical wards & $89(17.6)$ & $3(3.4)$ & $58(65.2)$ & $4(4.5)$ \\
\hline Pediatric intensive care unit & $86(17)$ & $4(4.7)$ & $42(48.8)$ & $5(5.8)$ \\
\hline Perioperative services & $59(11.7)$ & $3(5.1)$ & $12(20.3)$ & $1(1.7)$ \\
\hline Neonatal intensive care unit & $47(9.3)$ & $1(2.1)$ & $36(76.6)$ & $4(8.5)$ \\
\hline Emergency room & $23(4.5)$ & $4(17.4)$ & $11(47.8)$ & $1(4.3)$ \\
\hline
\end{tabular}

${ }^{*}$ Percentage of all opioid reports collected; ${ }^{\dagger}$ Percentage of total opioid reports for that particular location

TABLE 2

Stages in the medication process associated with opioid medication errors

\begin{tabular}{|c|c|c|c|c|c|c|}
\hline $\begin{array}{l}\text { Drug (number of } \\
\text { reports) }\end{array}$ & Prescribing, n (\%)* & Dispensing, n (\%)* & $\begin{array}{c}\text { Administration, } \\
\mathrm{n}(\%)^{\star}\end{array}$ & Monitor, n (\%)* & Checks, n (\%)* & Disposal, n (\%)* \\
\hline Morphine $(n=259)$ & $58(22.4)$ & $20(7.7)$ & $112(43.2)$ & $8(3.1)$ & $22(8.5)$ & $33(12.7)$ \\
\hline Fentanyl (n=96) & $7(7.3)$ & $4(4.2)$ & $28(29.2)$ & $5(5.2)$ & $13(13.5)$ & $39(40.6)$ \\
\hline Hydromorphone $(n=62)$ & $15(24.2)$ & $5(8.1)$ & $31(50)$ & $2(3.2)$ & $3(4.8)$ & $4(6.4)$ \\
\hline Codeine $(n=42)$ & $16(38)$ & $6(14.4)$ & $14(33.3)$ & $0(0)$ & $1(2.4)$ & $4(9.6)$ \\
\hline Oxycodone (n=11) & $0(0)$ & $0(0)$ & $7(63.6)$ & $1(9.1)$ & $3(27.3)$ & $0(0)$ \\
\hline
\end{tabular}

*Total number of reports for each opioid 
TABLE 3

Safety reports describing inappropriate opioid storage and disposal

\begin{tabular}{|c|c|c|c|c|c|c|}
\hline Time period & $\begin{array}{l}\text { Safety reports for all } \\
\text { medications, } n\end{array}$ & Opioid reports, $n$ & $\begin{array}{c}\text { Category A reports }^{\dagger}, \\
\text { n (\% of opioid reports for } \\
\text { that year) }\end{array}$ & $\begin{array}{l}\text { Reports describing } \\
\text { inappropriate opioid } \\
\text { disposal, } n\end{array}$ & $\begin{array}{c}\text { Perioperative care } \\
\text { unit }{ }^{\ddagger}, n\end{array}$ & $\begin{array}{l}\text { Pediatric intensive } \\
\text { care } \text { unit }^{\ddagger}, \mathrm{n}\end{array}$ \\
\hline $2004^{*}$ & 639 & 59 & $20(34)$ & 12 & 5 & 3 \\
\hline 2006 & 1326 & 111 & $33(29.7)$ & 22 & 9 & 1 \\
\hline 2007 & 1281 & 105 & $29(27.6)$ & 17 & 3 & 6 \\
\hline 2008 & 1452 & 121 & $22(18.2)$ & 17 & 2 & 9 \\
\hline
\end{tabular}

${ }^{*}$ Six-month period from July 1 to December $31 ;{ }^{\dagger}$ Category A refers to circumstances or events that have the capacity to cause error; ${ }^{\ddagger}$ Refers to location of reports describing inappropriate narcotic disposal

TABLE 4

Symptoms described in opioid safety reports

\begin{tabular}{|c|c|c|c|}
\hline & $\begin{array}{l}\text { Category B } \\
\text { reports, } \mathrm{n}\end{array}$ & $\begin{array}{c}\text { Category C-D } \\
\text { reports, } n\end{array}$ & $\begin{array}{c}\text { Category E-I } \\
\text { reports, } n\end{array}$ \\
\hline Total reports & 31 & 292 & 22 \\
\hline $\begin{array}{l}\text { Symptom described in } \\
\text { report }\end{array}$ & 0 & 30 & 17 \\
\hline $\begin{array}{l}\text { More than one symptom } \\
\text { described }\end{array}$ & 0 & 5 & 9 \\
\hline $\begin{array}{l}\text { Significant symptoms } \\
\text { described* }^{*}\end{array}$ & 0 & 10 & 15 \\
\hline Pain & 0 & 15 & 1 \\
\hline Drugs administered & 0 & 15 & 14 \\
\hline $\begin{array}{l}\text { Extra therapy required } \\
\text { stated as an outcome }\end{array}$ & 0 & 23 & 11 \\
\hline $\begin{array}{l}\text { Increased hospital stay } \\
\text { stated as an outcome }\end{array}$ & 0 & 0 & 4 \\
\hline
\end{tabular}

*Significant symptoms include one or more of the following: sedation, respiratory compromise, hypotension, bradycardia and code/arrest

\section{DISCUSSION}

The objective of the present project was to examine all voluntary safety reports in a pediatric institution describing issues with opioids to better define problematic individual opioid agents, severity of opioid errors, the circumstances that cause opioid medication errors in our institution and the areas where we can best hope to make an impact in the coming years. We also aimed to highlight the potential benefits of an institution-wide audit of opioid errors. We promote the notion that individual institutions, and each clinical area within those institutions, should perform a regular audit of medication errors and, in particular, opioid errors. The Institute for Safe Medication Practices recently released a phase 2 report (19) describing multiple measures to address issues of pediatric opioid safety at all levels of clinical care. Regular audits and analyses of opioid errors in pediatric practice will better guide local implementation and ongoing assessment of the success of such recommendations and proposals.

The results of the present study demonstrated that opioids were the second most frequently reported drug class involved in errors at our institution; morphine was the most commonly reported opioid and most frequently reported opioid that caused patient harm (13 of 22 opioid reports that described harm). The results also demonstrated that in the first four-and-a-half years of safety reporting we did not consistently affect or decrease the reporting rate of opioid errors per 100 patient days. The results suggested that the areas requiring the greatest focus for decreasing opioid error in our institution were opioid administration (especially morphine), disposal and safe 'handling' of opioids, identification of pain and inadequate analgesia as an adverse event, and - to a lesser extent - awareness of codeine and hydromorphone as opioids with potential for error and significant pediatric harm.

Internal pharmacy purchasing data confirmed that morphine is the most prescribed and administered opioid in our institution. Almost one-half of all safety reports describing error with morphine identified an administration error. In total, 192 opioid administration errors were identified. Initiatives that focus on administration issues (reinforced education regarding the 'five rights', checking medication with a parent or substitute decision maker at the point of administration, specific personnel on the unit/ward for drug administration alone, and barcoding of medications) may affect opioid error associated with morphine in the future. However, one qualitative project within our institution, initiated after the findings of the present project, proposes to conduct a standardized interview each time an opioid administration error occurs to better characterize where the 'five rights' are breaking down, what factors are contributing to these errors and how we can best arrive at a solution for opioid administration errors. Factors such as patient acuity, work detail and duty, distraction during medication administration, and psychosocial and human factor analysis will all be used to better understand the etiology of errors in opioid administration.

A previously unrecognized institutional issue identified by voluntary reporting in the present project was unsafe handling of opioids in particular, the inappropriate discarding of partly used fentanyl ampoules. Steps taken to publicize this issue among members of perioperative services coupled with encouragement among all hospital staff to continue to report such incidents resulted in steady decreases of these particular opioid medication errors in the perioperative care unit. However, no such initiatives took place in other clinical areas, where an increased reporting of this particular type of category A opioid medication error was observed over the same time period. Not all institutions can afford to implement automated drug dispensing systems, and this issue may represent an important area of opioid safety not previously reported in the literature, ie, responsible handling of narcotics to decrease exposure of other health care workers to addictive substances. To quote from another publication, "Critical to any risk reduction strategy is the creation of an organizational culture and environment in which all staff and patients are encouraged and expected to prevent errors, no matter what their source, and to effectively communicate, coordinate, and resolve identified or suspected errors, discrepancies, and issues" (20).

A total of 314 opioid medication errors reached the patient. Forty-seven patients complained of symptoms that were transcribed to the safety report and 16 of these reports described pain as the predominant symptom. This may have resulted from correct administration of an underprescribed dose, incorrect administration of a correctly prescribed dose, faulty/inoperative equipment (eg, patient-controlled analgesia or infusion pumps), omission of dose, or administration of a dose to the wrong patient, thereby depriving another patient of their analgesia. Whatever the source of error, we observed that the reports of opioid medication errors often described patient pain. The development of trigger tools to address opioid medication errors focuses on target items such as naloxone use, antiemetic use and supplemental oxygen but, to date, has not included pain as a trigger $(13,21,22)$. In hospital practice, trigger tool measurement of adverse medication events has demonstrated that anticoagulants, sedatives and opioids are often most responsible for causing patient harm (23). Institutions such as our own, that have focused safety efforts on these medications, have demonstrated some reduction in ADE reporting (20). The 
identification of pain as a symptom associated with voluntary reports describing opioid medication errors suggests that we could further adjust the focus of trigger tools and multicentre initiatives to better address the etiology, spectrum and effects of opioid medication errors in pediatric hospital practice. To consider pain an adverse event is controversial and carries with it an administrative and methodological workload, but it may prove to be a very effective method for addressing the problems of inadequate pain assessments and patient dissatisfaction with postoperative analgesia (24).

Opioid medication reports identifying prescription errors (Table 2) demonstrated that an incorrect prescription of morphine accounts for over 22\% (58 of 259) of all opioid medication errors involving morphine in our institution. However, reports identifying prescription errors with codeine demonstrated a higher proportional frequency of reporting (38\% of all codeine reports), suggesting a possible deficiency of knowledge when prescribing codeine. This may be due to regular turnover of medical and surgical postgraduate personnel in training, the decision of whether to combine codeine with acetaminophen and unfamiliarity with pediatric dosing guidelines. Perhaps regularly repeated education for new hospital staff could be of benefit in this area. Hydromorphone demonstrates a similar proportion of prescription error reports when compared with morphine but a greater proportion of administration errors. The observation that codeine and hydromorphone opioid medication errors comprised three of the four most severe incident reports resulting in patient harm suggests that interventions are required to improve safety with these opioids. A recent Institute for Safe Medicine Practices bulletin (24) named fentanyl as the fourth most frequently reported medication to cause harm in pediatric patients. Neither codeine nor hydromorphone were identified by this national collaborative comprising 17 pediatric organizations submitting 4000 incidents, 305 of which caused harm, over a time period similar to our own project. This serves as a timely reminder that local audit must be regularly performed to assess the individual needs of one's own institution. In follow-up to our findings, an introductory lecture now takes place in the first week of January and July for all new surgical personnel to address issues with pain and pain assessment, codeine and opioid dosages, and prescription resources such as online formularies and hospital recommendations. This lecture is jointly delivered by the chief of perioperative services and the director of the pain centre. Hydromorphone has also been added to the hospital's list of highly toxic medications.

The present project is not without limitations. First, this was a retrospective study of de-identified safety reports with a finite amount of available information. However, familiarity with the information normally contained within these reports and familiarity with the review process at the hospital committee level allowed us to design data forms in such a fashion that emphasis was on the report itself, the location of the report, the medications involved, and extracting and categorizing all information from the report to optimize reliable data available for audit. In this fashion, we were able to examine and establish the nonpatient-related factors involved with opioid medication errors in this institution. A second limitation is that symptoms described in the present study are those reported by the health care worker while filling out the safety report as opposed to those symptoms experienced by the patients themselves or reported in the patient chart. However, the safety report still describes the health care worker's experience of the error and, as such, can still be considered an accurate description of the event as it transpired. Third, voluntary reporting systems underreport frequencies and incidences of error. It is long established that voluntary reporting systems significantly underreport true adverse event rates, sometimes by as much as a factor of $20(25,26)$. However, for the purposes of the present project, we were interested in neither absolute frequencies and rates, nor comparison of our incidence of error rate with previous publications. For the purposes of the project, we did not use a denominator when examining opioid error reports because a denominator implies the ability to compare rates, and the actual rates of some errors would be low due to expected underreporting. Instead, we focused on examining the spectrum of all opioid medication errors as reported by hospital health care workers over a prolonged time period. Despite the fact that some errors were reported infrequently, the absence of a denominator meant that we could simply focus on what arose often, where it occurred and what it involved. In this manner, we could focus on the issues that affected us most throughout the institution, and which opioids and which phase of the medication process we needed to monitor most. Nevertheless, some factors suggest that our data were more applicable than those normally assigned to voluntary reporting systems. First, we reported similar rankings of categories of medications reported (ie, antimicrobials, analgesics [sedatives and electrolytes], nutritional support, fluids and diuretics, and anticonvulsants) in other publications $(10,21,22)$. Second, we identified and described unique issues not previously reported such as pain and inappropriate opioid disposal. Publications that exclusively reported ADEs failed to provide data describing category A errors that have a potential for future error or category B errors that are intercepted before reaching the patient. Such practices would have excluded more than 300 reports from analysis in the present project, including 292 clinical opioid errors that actually reached hospitalized pediatric patients.

\section{CONCLUSION}

The characteristics of opioid medication errors reported in our institution suggested that opportunities for improvement in opioid safety should focus on decreasing the high incidence of morphine errors and opioid administration errors, increasing worker safety by decreasing the incidence of inappropriate opioid disposal and storage, and acknowledging the identification of pain as a common sequela of opioid error and as a reportable adverse event.

\section{APPENDIX 1 \\ National Coordinating Council for Medication Error Reporting and Prevention index for categorizing medication errors}

\begin{tabular}{cc}
\hline Category A & $\begin{array}{c}\text { Circumstances or events that have the capacity to cause } \\
\text { error }\end{array}$
\end{tabular}

Category B An error occurred but the error did not reach the patient (an 'error of omission' does reach the patient)

Category C An error occurred that reached the patient but did not cause patient harm

Category D An error occurred that reached the patient and required monitoring to confirm that it resulted in no harm to the patient and/or required intervention to preclude harm

Category E An error occurred that may have contributed to or resulted in temporary harm to the patient and required intervention

Category F An error occurred that may have contributed to or resulted in temporary harm to the patient and required initial or prolonged hospitalization

Category G An error occurred that may have contributed to or resulted in permanent patient harm

Category $\mathrm{H} \quad$ An error occurred that required intervention necessary to sustain life

Category I An error occurred that may have contributed to or resulted in the patient's death

Copyright 2001 National Coordinating Council for Medication Error Reporting and Prevention. All rights reserved (16)

\section{REFERENCES}

1. Kohn LT, Corrigan JM, Donaldson M. Institute of Medicine (IOM) Report: To Err is Human: Building a Safer Health System. Washington, DC: National Academy of Sciences, 1999.

2. Wong IC, Ghaleb MA, Franklin BD, Barber N. Incidence and nature of dosing errors in paediatric medications: A systematic review. Drug Safety 2004;27:661-70. 
3. Kaushal R, Jaggi T, Walsh K, Fortescue EB, Bates DW. Pediatric medication errors: What do we know? What gaps remain? Ambul Pediatr 2004;4:73-81.

4. Bates DW, Spell N, Cullen DJ, et al. The costs of adverse drug events in hospitalized patients. JAMA 1997;277:307-11.

5. Classen DC, Pestotnik SL, Evans RS, Lloyd JF, Burke JP. Adverse drug events in hosptalized patients: Excess length of stay, extra costs, and attributable mortality. JAMA 1997;277:301-6.

6. Van den Anker JN. Managing drugs safely. Semin Fetal Neonatal Med 2005;10:73-81.

7. Stucky ER; American Academy of Pediatrics Committee on Drugs; American Academy of Pediatrics Committee on Hospital Care. Prevention of medication errors in the pediatric inpatient setting. Pediatrics 2003;112:431-6.

8. Ceci A, Felisi M, Catapano M, et al. Medicines for children licensed by the European Agency for the Evaluation of Medicinal Products. Eur J Clin Pharmacol 2002;58:495-500.

9. Gray JE, Goldmann DA. Medication errors in the neonatal intensive care unit: Special patients, unique issues. Arch Dis Child Fetal Neonatal 2004;89:F472-3.

10. Kaushal R, Bates DW, Landrigan C, et al. Medication errors and adverse drug events in pediatric inpatients. JAMA 2001;285:2114-20.

11. Holdsworth MT, Fichtl RE, Behta M, et al. Incidence and impact of adverse drug events in pediatric inpatients. Arch Pediatr Adolesc Med 2003;157:60-5.

12. Institute for Safe Medication Practices (ISMP) Canada Safety Bulletin, April 7th 1999. The "five rights". <www.ismp.org/ Newsletters/acutecare/articles/19990407.asp> (Accessed on February 16, 2011).

13. Sharek PJ, McClead RE, Taketomo C, et al. An intervention to decrease narcotic-related adverse drug events in children's hospitals. Pediatrics 2008;122:861-6.

14. Sharek PJ, Horbar JD, Mason W, et al. Adverse events in the neonatal intensive care unit: Development, testing, and findings of an NICU-focused trigger tool to identify harm in North American NICUs. Pediatrics 2006;118:1332-40.
15. National Coordinating Council for Medication Error Reporting and Preventions. NCC MERP: The first ten years - defining the problem and developing solutions. December 2005. <www.nccmerp. org/pdf/reportFinal2005-11-29.pdf> (Accessed on February 16, 2011).

16. National Coordinating Council for Medication Error Reporting and Prevention. Types of Medication Errors. <www.nccmerp.org/ medErrorCatIndex.html> (Accessed on February 16, 2011).

17. Trissel LA. Medication errors: Integrating individual and system accountability. Am J Health Syst Pharm 1999;56:1263-4.

18. Koren G. Trends of medication errors in hospitalized children. J Clin Pharmacol 2002;42:707-10.

19. MacLaren Chorney J, McGrath P, Finley GA. Pain as the neglected adverse event. CMAJ 2010;182:732.

20. Rozich JD, Resar RK. Medication safety: One organization's approach to the challenge. J Clin Outcomes Manag 2001;8:27-34.

21. Takata GS, Taketomo CK, Waite S, for the California Pediatric Patient Safety Initiative. Characteristics of medication errors and adverse drug events in hospitals participating in the California Pediatric Patient Safety Initiative. Am J Health Syst Pharm 2008;65:2036-44.

22. Hicks RW, Becker SC, Cousins DD. Harmful medication errors in children: A 5-year analysis of data from the USP's MEDMARX program. J Pediatr Nurs 2006;21:290-8.

23. Resar R. Will, ideas, and execution: Their role in reducing adverse medication events. J Pediatr 2005;147:727-8.

24. Institute for Safe Medication Practices (ISMP) Canada Safety Bulletin. National collaborative: Top 5 drugs reported as causing harm through medication error in paediatrics. August 31st 2009, Volume 9, Number 6. <www.ismp-canada.org/download/ safetyBulletins/ISMPCSB2009-6-NationalCollaborativeTop5DrugsReported.pdf> (Accessed on February 16, 2011).

25. Resar RK, Rozich JD, Classen DC. Methodology and rationale for the measurement of harm with trigger tools. Qual Saf Health Care 2003;12(Suppl 2):ii39-ii45.

26. Evans SM, Berry JG, Smith BJ, et al. Attitudes and barriers to incident reporting: A collaborative hospital study. Qual Saf Health Care 2006;15:39-43. 


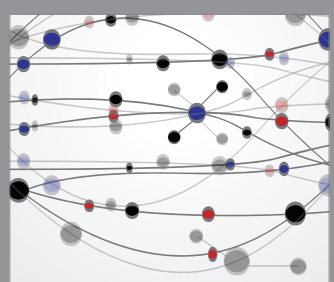

The Scientific World Journal
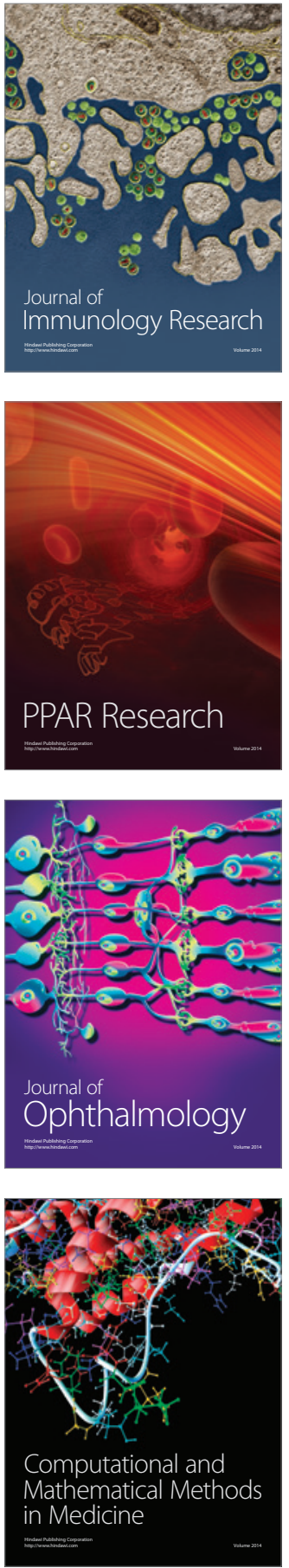

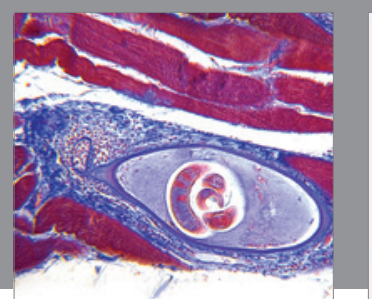

Gastroenterology Research and Practice

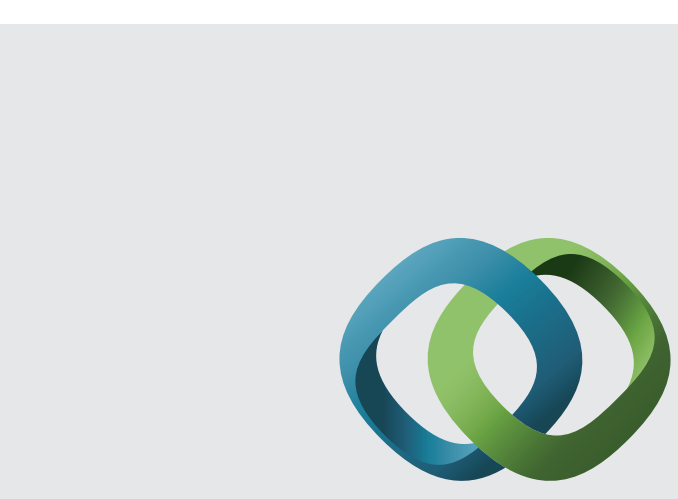

\section{Hindawi}

Submit your manuscripts at

http://www.hindawi.com
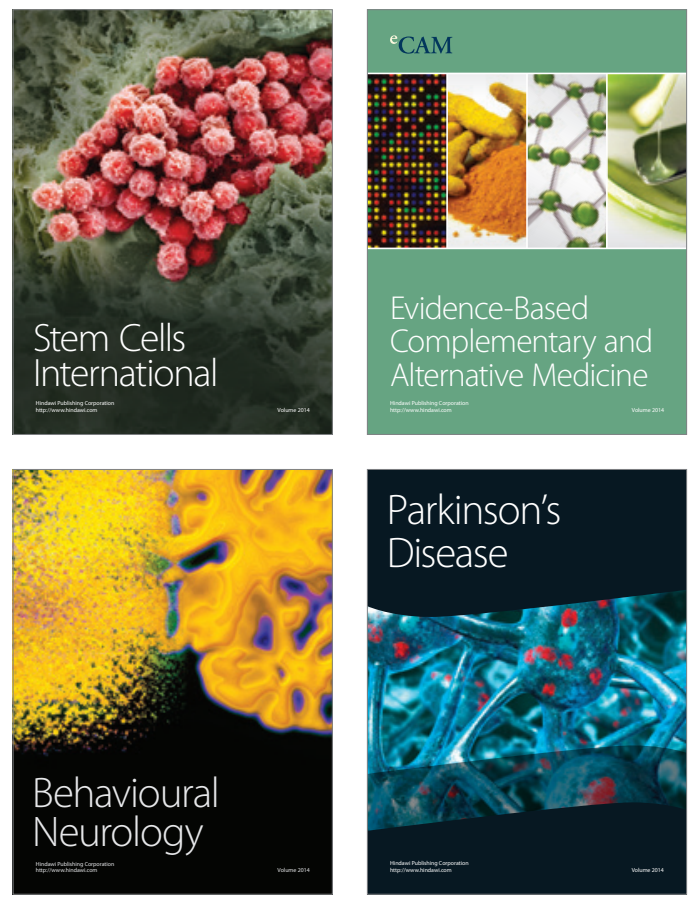
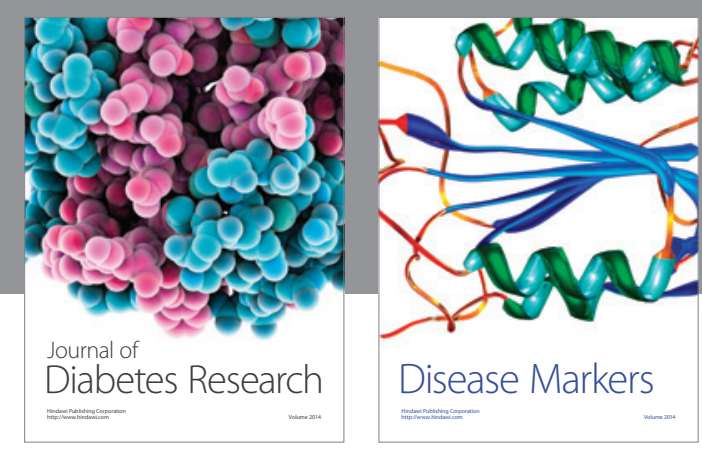

Disease Markers
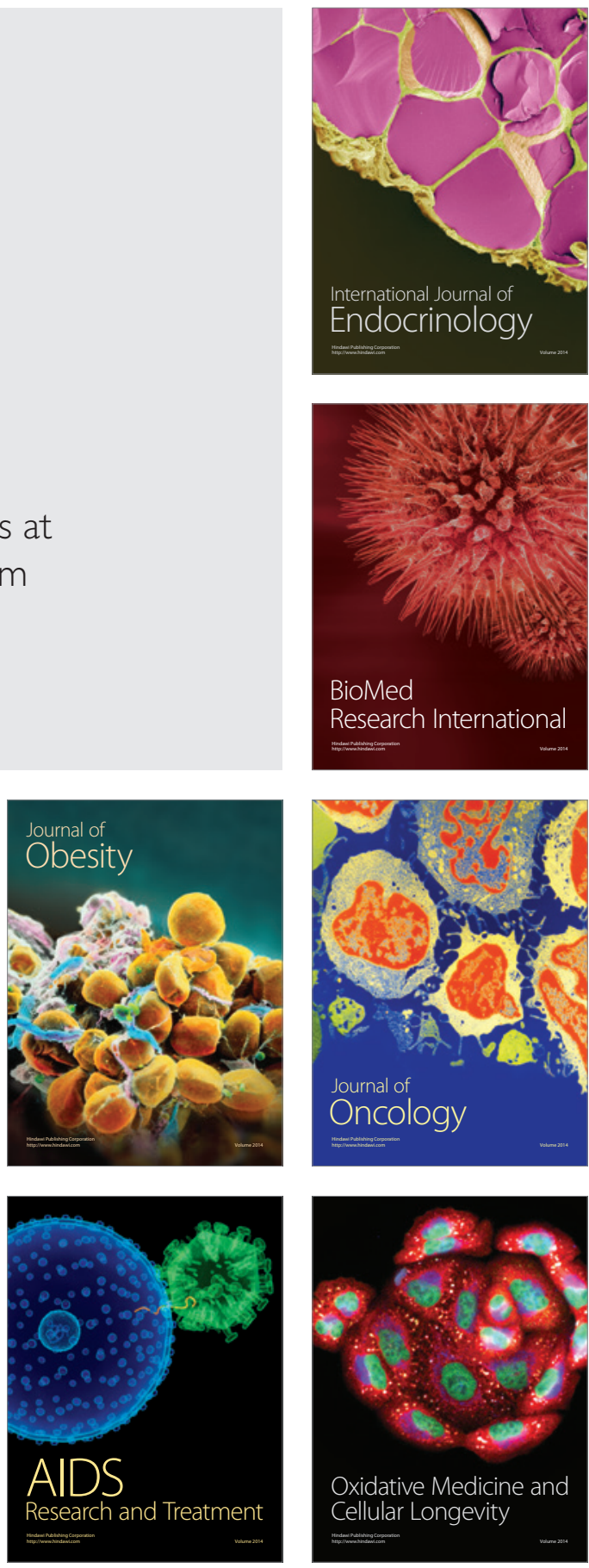